\title{
Neuroprogression: the hidden mechanism of depression
}

This article was published in the following Dove Press journal:

Neuropsychiatric Disease and Treatment

\author{
Norma A Labra Ruiz' \\ Daniel Santamaría \\ del Ángel' \\ Hugo Juárez Olguín ${ }^{2}$ \\ Miroslava Lindoro Silva ${ }^{2}$ \\ 'Laboratory of Neurosciences, \\ Instituto Nacional de Pediatria (INP), \\ Mexico City, Mexico; ${ }^{2}$ Laboratory of \\ Pharmacology, Instituto Nacional de \\ Pediatría (INP), Faculty of Medicine, \\ Universidad Nacional Autónoma de \\ Mexico, Mexico City, Mexico
}

\begin{abstract}
For many years, depressive disorder (DD) was considered a transient and natural disease of people's mood. Its etiology had been attributed mainly to biochemical alterations of the monoamines and their receptors. Nevertheless, its prevalence and considerable impact on the family and social environment of those afflicted by it have placed the disease as a global public health problem. Neuroprogression is the term used to describe the changes in several psychiatric conditions evidenced and observed in the clinical manifestations, biochemical markers, and cerebral structures of the patients with major depressive disorder (MDD), which frequently overlap with neurodegenerative disorders. DD is considered a potentially aggressive state of neuronal deterioration involving apoptosis, reduced neurogenesis, decreased neuronal plasticity, and increased immune response. Clinically, it encompasses a poor response to treatment and an increase in depressive episodes, both of which bring about vulnerability and decline of functions associated with structural changes in the brain. The interest of this work is to review the metabolic processes involved in the morphologic alterations in the limbic system reported in patients with MDD, as well as the neurologic bases of this complex pathology that include environmental stress, genetic vulnerability, alterations in the neurotransmission, and changes in the neuroplasticity, all of which today bring into limelight a mechanism of progressive neuronal damage.
\end{abstract}

Keywords: depressive disorder, monoamines, neuroprogression, neuroendocrine

\section{Introduction}

Depressive disorder (DD) is a pathology of the mood that involves feelings of deep pain, anger, frustration, and loneliness that impede the patients from carrying on with their normal life. ${ }^{1}$ It is one of the oldest psychiatric disorders of which there is evidence. Physiologically, it is manifested as chemical imbalance in the brain, a situation that constitutes the main affectation seen in more than half of the patients in outpatient psychological visits. Epidemiologically, it represents $13 \%$ of all mental illnesses, fifth in place as the cause of disability in the world and women:men affectation ratio of $2: 1$. It is characterized mainly by dejection, anhedonia (loss of pleasure), general disinterest, reduced energy or fatigue, sleep and appetite disorders, somatic discomfort, concentration and memory failures, feelings of guilt and low self-esteem, poor vision of the future, comorbidity with other diseases, and, frequently, the possibility of suicide; hence, its attention is of paramount importance. ${ }^{2,3}$

Long before the birth of psychiatric medical specialist, the origin of DD and its treatment, just like the rest of mental disorders, were based on magic and empirical environmental therapy. Nevertheless, in the mid-20th century, the debut and confirmation of the monoaminergic hypothesis, implicating serotonin neurotransmitters (5-HT) and noradrenaline (NA), in the treatment of depression gave way to
Correspondence: Hugo Juárez Olguín Laboratorio de Farmacología, Instituto Nacional de Pediatría, Avenida Imán, $N^{\circ}$ I, 3rd piso Colonia Cuicuilco CP 04530, México City, México Tel +52 $555616 \quad 1489$ $\mathrm{Fax}+52555616 \quad 1489$ Email juarezol@yahoo.com 
authentic search for drugs that would specifically act on one or both monoamines. ${ }^{4}$ This hypothesis postulated that the pathophysiologic basis of depressive behavior has, as its pivot, the relative or absolute decrease of these monoamines in the synaptic space as a result of either the insensitivity of their receptors, decrease in their vesicular storage, or their removal from the synaptic space. ${ }^{5}$

5-HT, an indolamine synthesized from tryptophan, together with the catecholamines (NA, adrenaline [A], and dopamine [DA]) synthesized from tyrosine are concentrated within vesicles in the terminal region of the neurons. From here, they are released into the synaptic space during the process of nerve transmission. The action of 5-HT ends when it is recaptured and degraded by monoamine oxidase (MAO) enzyme located in the outer mitochondrial membrane of the neurons and glial cells. ${ }^{6}$

This evidence was based on the development of medications for the treatment of DD. Its therapeutic approach was built on accidental discovery during the clinical trials of iproniazid, an antituberculous inhibitor of the MAO, which, like the tricyclic drugs, increased the availability and the excitatory effects of neurotransmitters in the reward and pleasure centers of NA and 5-HT systems located in the hypothalamus and in the surrounding areas of the limbic system. The end result of this increase is manifested in "mood elevation". It was in this way that in 1950, the first antidepressant drug, fluoxetine, a selective serotonin reuptake inhibitor, came into being. Shortly after, imipramine, a tricyclic drug derived from chlorpromazine with better antidepressant activity, was discovered. This discovery led to the development of numerous antidepressant drugs such as fluvoxamine, paroxetine, sertraline, and citalopram that function as inhibitors of the reuptake of 5-HT, NA, and selective of the MAO. ${ }^{7}$ Subsequently, the discovery of the reversible MAO inhibitor, moclobemide, and 5-HT and DA reuptake inhibitor, bupropion, was made. In the 1990s, mirtazapine, a drug with combined effect on noradrenergic and serotoninergic receptors, as well as reboxetine, an NA reuptake inhibitor, and later the dual drugs, venlafaxine and duloxetine, were developed. The last two are called duals for their double inhibiting action on the reuptake of both 5-HT and NA. Currently, clinical psychiatry has more than 30 highly effective advanced agents such as agomelatine, a melatonin agonist, for use in the treatment of DD. ${ }^{8}$

\section{Therapeutic response}

The treatments administered in the initial phase of DD with antidepressants have a relative efficacy of $23 \%$ in a period of 6-8 weeks, although $70 \%$ of the patients diagnosed with major depression do not achieve a response and this lack of response has been associated with poor functional evolution. ${ }^{7}$ It is proposed that one of the mechanisms of action of antidepressant drugs occurs through the increase of brainderived neurotropic factor (BDNF), which decreases with the presence of corticosterone.

The study of the endogenous origin of DD has revealed the existence of a complex interaction between genetic, epigenetic, and psychosocial factors associated to a physiologic decompensation of the nervous, endocrine, and immune systems. It has been observed that the first depressive episodes appear after some stressful events in which half of the patients depict increased cortisol accompanied by hypothalamic-pituitary-suprarenal (HHS) gland axis dysfunction; elevation of inflammatory and oxidative stress (OS) indicator parameters; and in critical cases, alteration in brain morphology.9,10

\section{Structural changes}

Brain imaging studies applied to patients with MDD have demonstrated a selective structural change of several neuronal circuits that bring into evidence deterioration in cell plasticity and resilience. ${ }^{11}$

The findings reported indicate that, different from other pathologies such as Parkinson's and Huntington's diseases where the alterations are located in a specific region of the brain, DD involves a complex set of structures that form the highly organized circuits involved in the control of reactions to stress, memory, attention, sexual instincts, and to the construction of emotions such as pleasure, fear, aggressiveness, personality, and behavior, ${ }^{12}$ which are found to be hyperactive in stress responses. ${ }^{13}$

The most obvious structural changes in the brain of depressed patients are a decrease in the integrity of the white matter and frontal cortex, reduction in the volume of the frontal lobe, prefrontal orbital lobe, circumvolution of the frontal corpus callosum, as well as in the complex set of structures and neuronal circuits of the limbic system involved in the control of reactions to stress, memory, attention, sexual instincts, and to the construction of emotions such as pleasure, fear, aggressiveness, personality, and behavior. ${ }^{12,14}$

The limbic system is composed by limbic cortex, cingulate gyrus, parahippocampal gyrus, hippocampal formation, dentate gyrus, hippocampus, subauricular complex, amygdala, septal area, and hypothalamus. ${ }^{12}$ The main neuroanatomical circuits involved in the regulation of the mood are considered to be:

1. the limbic-thalamic-cortical circuit, which includes the amygdala, the dorsal-medial nuclei of the thalamus, and 
2. the prefrontal cortex, both medial and ventrolateral as well as the limbic-striated-pale-thalamic-cortical circuit. ${ }^{15}$

During the depressive crisis, the most obvious changes are reported in the hippocampus and amygdala. It has been suggested that the reduction in the hippocampal volume is as a result of neuronal loss caused by certain neurotoxic effect triggered by glucocorticoids, because hippocampal volumes are considerably smaller in the patients when compared with those in remission. ${ }^{16}$

The hippocampus is formed by three distinct zones organized in bands that go from the anterior to the posterior part within the temporal lobe. These bands together form a cylinder. Apart from being involved in adult brain neurogenesis, they express numerous receptors of glucocorticoids and have multiple connections with prefrontal cortex and amygdala. The amygdala is connected to the hypothalamus and laterodorsal tegmental nucleus responsible for the activation of DA, NA, and A neurotransmitters. As the disease progresses, relapses that damage the overall functioning increase the recurrence to hospitalization with decreased response to pharmacologic treatment.

The initial physiologic explanation of this condition has been attributed to endocrine desynchronization involving the following mechanism:

After a stressful stimulus, the neuropeptides, corticotropinreleasing factor (CRF), and arginine-vasopressin (AVP) activate the hypothalamo-pituitary-adrenal (HPA) axis to produce and release adrenocorticotropic hormone (ACTH). This hormone stimulates the suprarenal glands to synthesize and release glucocorticoids, mainly cortisol in humans and corticosterone in animals. The glucocorticoids are responsible for inhibiting, by negative feedbacks, the secretion of CRF and AVP by the hypothalamus and, therefore, the secretion of ACTH by the pituitary gland. In depressed patients, this response does not function normally (Figure 1). This abnormal functioning usually leads to the establishment of constant and elevated levels of cortisol that triggers an overstimulation of this axis and provokes a series of alterations in the metabolism of serotonin and DA (Figure 2). ${ }^{17}$ A mitochondrial energy dysfunction favors the presence of OS and proinflammatory processes with a repercussion in neurogenesis and brain plasticity.

The negative impact of the hypercortisolemia in the monoaminergic transmission of 5-HT, NA, and DA is due to the disruption of their receptors located in the limbic regions (prefrontal cortex, amygdala, hippocampus, and hypothalamus) that are extremely sensitive to the hormones released during stress. ${ }^{18}$ Cortisol induces an increase in the expression of the gene encoding serotonin transporter,

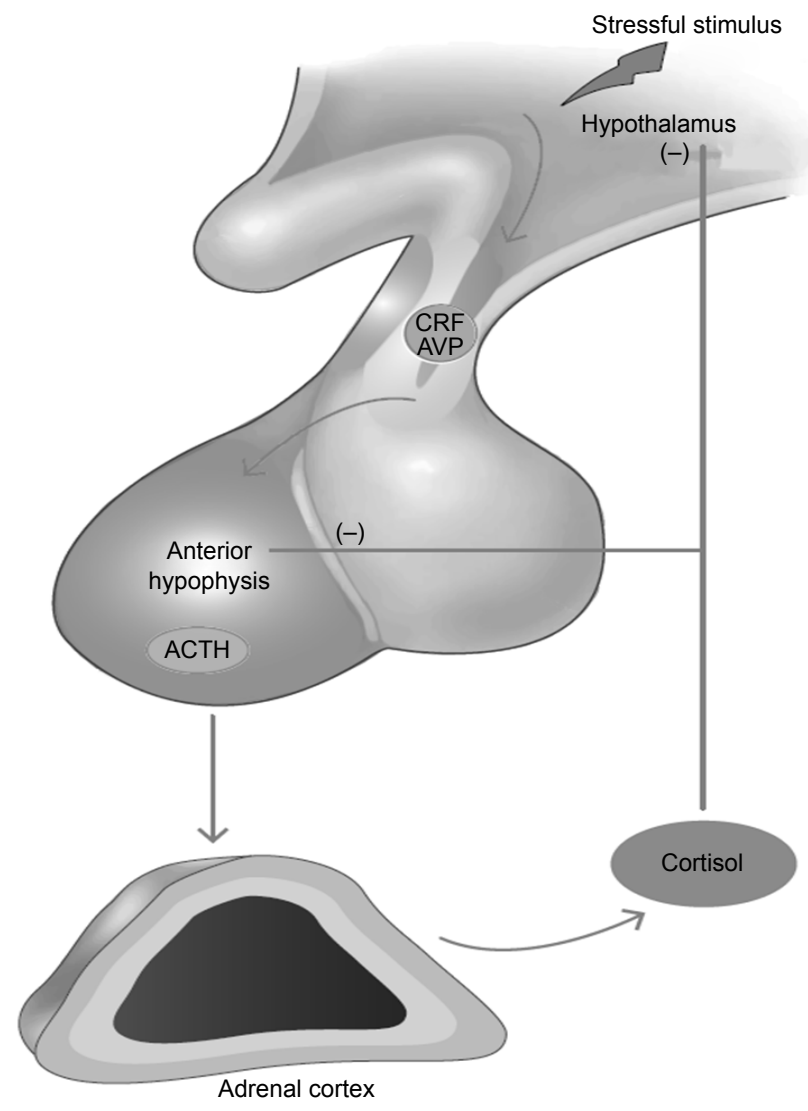

Figure I The glucocorticoids are responsible for inhibiting, by negative feedbacks, the secretion of CRF and AVP by the hypothalamus and, therefore, the secretion of ACTH by the pituitary gland.

Note: In depressed patients, this response does not function normally.

Abbreviations: ACTH, adrenocorticotropic hormone; AVP, arginine-vasopressin; CRF, corticotropin-releasing factor.

associated with a subsequent elevation of its reuptake, ${ }^{19}$ and a substantial increase in its uptake by the peripheral blood lymphocytes and cortical brain cells. Serotonin exerts an important action in the mood, behavior, movement, pain appreciation, sexual activity, appetite, endocrine secretion, cardiac functions, and sleep-awake cycle. ${ }^{20}$

The catecholamines (NA and DA) play an integral role in DD pathophysiology. NA is a neuromodulator that activates the amygdala and thereby favors aversive behavior and fear, while DA is associated with effective motor functions and neuroendocrine regulation. ${ }^{21-23}$ The relevance of these neurotransmitters is based on the success obtained from the tricyclic drugs and the MAO inhibitors used in the treatment of DD. These drugs increase the availability of catecholamines and indolamines, thereby favoring their dispositions in the reward and pleasure centers of the hypothalamus and the surrounding areas. ${ }^{24}$ Nevertheless, even when the antidepressants block the reuptake of the neurotransmitters within hours after their administration, the effects appear weeks after, ${ }^{25}$ thus indicating the participation of other mechanisms such as the 


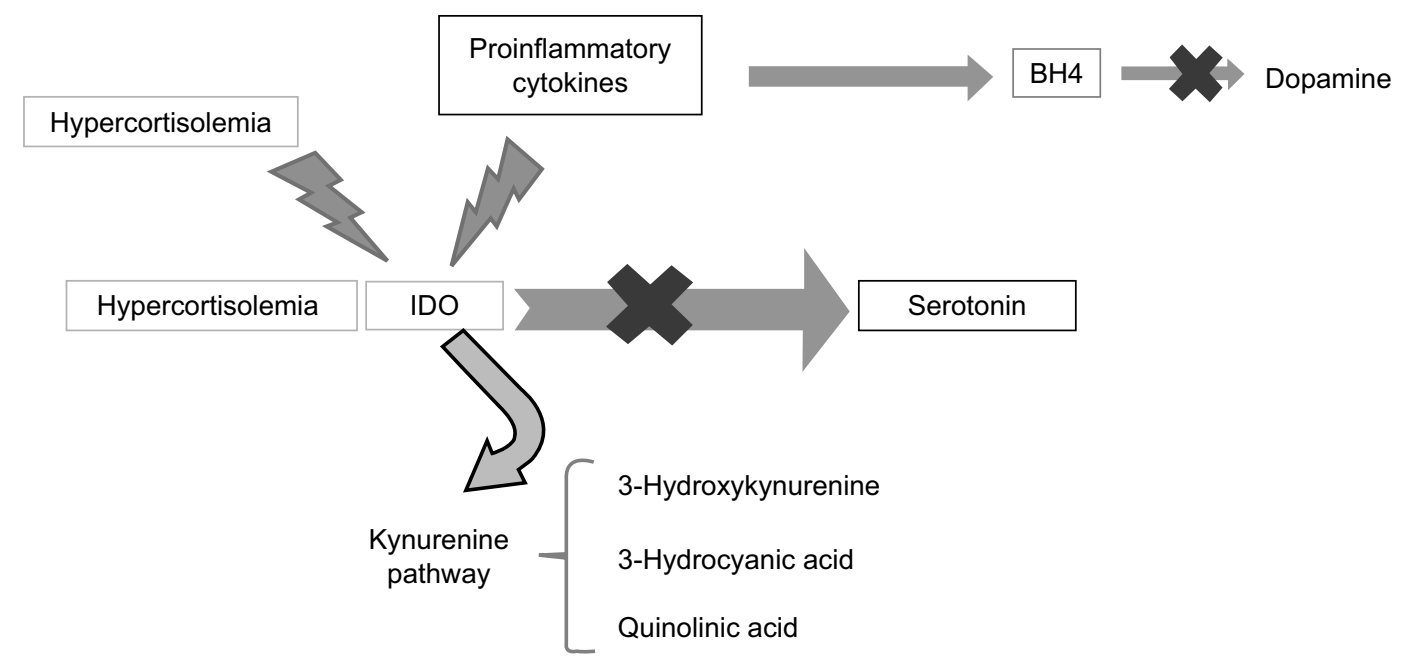

Figure 2 Inhibition and synthesis of serotonin and dopamine.

insensitivity of the receptors or failure in their expression for genetic predisposition. ${ }^{26}$ Within the genetic causes of depression, a good number of studies have arrived at the conclusions that:

The disease does not follow the classic pattern of Mendelian inheritance but consider that it follows a susceptible threshold model. It is considered that there is a certain "susceptibility for the development of the disease" distributed randomly in the population, in such a way that only those who exceed a certain threshold of this variable will manifest the disorder. ${ }^{27}$ The non-Mendelian genetic predisposition found in the allelic variants of some patients is related to the synthesis and expression of genes encoding proteins involved in the synthesis of tyrosine hydroxylase enzyme that limits DA synthesis. ${ }^{28}$

The findings have shown allelic variants in the genes encoding the serotonin receptors called " $\mathrm{s}$ " and "l" alleles (s for short and 1 for long) that represent the short and long versions of the gene. The "s" version is associated with low transcriptional efficiency of serotonin transporter compared with the "l" version, in such a way that in situations of high stress, people "s"/“l" or "s"/"s" are more disposed to develop a DD than people "l"/"l". The failure in chromosome 3 has been associated with severe depression. ${ }^{29}$ Other genes responsible for encoding for the synthesis of neurotransmitter-metabolizing enzymes such as MAO A and catechol-O-methyltransferase and the sirtuline-1 genes coupled with phosphor lysine phosphor histidine located in chromosome 10 involved in the mitochondrial formation ${ }^{30}$ have been implicated, although their failure seems to be indirectly affected by other mechanisms like OS, which will be discussed later.
The brain is constantly in a dynamic process imposed by new challenges that vary with the sensory inputs from the environment. One such process is neuroplasticity, which is the ability of the brain to form and reorganize synaptic connections to respond to injury, new knowledge, or experience. Sometimes this process achieves greater efficacy through stimulation and on other occasions lower or even null efficiency due to processes of neurodegeneration. Another such process is the establishment of alternative interconnection pathways that overlap with neuronal degeneration commonly called neurodegeneration. ${ }^{31}$

The physiologic changes related to the dynamics of adaptation to the environment and to stress, which are cumulative and involve small and constant changes in the central nervous system structures, were observed and described at the beginning of the decade of the 1990s by Robert Post. ${ }^{32}$

Post suggested that the physiology of the behavioral disorders could be understood as neuronal modification characterized by its chronic, phasic, and progressive course, associated with the physiologic process of cellular aging that from syndromic, symptomatic, and functional point of view makes it difficult to return to the previous state after each episode. ${ }^{33}$

The likelihood that these modifications were involved at the neuroplasticity level and not only in the imbalance of neurotransmitters or of the expression of their receptors in the development of DD led to investigation of other mechanisms that could include neurotrophic factors, inflammatory events, and even OS. ${ }^{34-36}$

\section{Neuroprogression}

The brain is constantly reorganizing by neuroplasticity and tries to achieve greater efficiency through neurodevelopment 
but on occasions, it establishes inefficient and incorrect alternative interconnection routes in phasic and progressive process called neuroprogression. ${ }^{31}$ Strictly speaking, neuroprogression is defined as neuronal changes that include mild degenerative processes, intracellular signaling dysfunctions, apoptosis, and decreased plasticity and neurogenesis. This process, which begins with mild onset, exacerbates with every passing crisis episode and with time provokes loss of cognitive abilities such as memory and decisionmaking. 37,38

In depression, the reduction in the size of frontal lobes, prefrontal orbital cortex, circumvolution of the frontal corpus callosum, hippocampus, and amygdala seems to reflect a decrease of neurogenesis, mitochondrial dysfunction, and an imbalance in HHS axis in depressed patients. The neurons of these regions in DD patients present failed reorganization or lesser efficacy in neuronal plasticity than atrophy or death. ${ }^{39}$ In this disorganization, there is a fundamental imbalance of the glial function, because such disorganization affects the level of cerebral microcirculation and control of excitability, and it is reflected in loss of glia-neuronal interactions, the amount of synapsis, and regulation of neurotransmitters, especially the monoamines in the brain areas that regulate emotions. Faced with a signal of inflammation, the neurons generate nitrogen and oxygen reactive species (RS) and secrete inflammatory cytokines the paracrine effect of which establishes a continuous circuit of self-activation. ${ }^{40}$ The induction of the microglial activation is involved in the deviation of metabolism of tryptophan to kynurenine, in the stimulation of the HPA axis and in the resistance to glucocorticoid receptors. This process known as reactive gliosis leads to a morphologic change of the cell body of the microglia, making their cell bodies to enlarge and the dendrites to become thicker or to be completely eliminated when the cell becomes amoeboid, thus reducing the number of its branches. When there is reactive gliosis of the astrocytes, the synthesis and release of neurotrophic factors necessary for the survival, differentiation, cell growth, and regulation of glutamate are progressively reduced due to the loss of their transporters - $\mathrm{EAAT}_{1}$ and $\mathrm{EAAT}_{2}-$ in the gray matter. ${ }^{41}$

The serotonergic system, in particular, seems to have a more active participation in the neuroprogressive process because it usually acts like neurogenesis-stimulating factor by the expression of BDNF. ${ }^{42}$ This factor promotes inflammatory mechanism, thus activating the monocytes and NK cells. It indirectly regulates the production of interferon gamma (IFN- $\gamma$ ) by establishing cytotoxicity. Serotonin also triggers the release of corticotropin-releasing hormone by the hypothalamus and in this way activates the HHS axis to favor the liberation of cortisol into the bloodstream. ${ }^{43}$ This is why its synthesis and brain levels have a delicate regulation.

The decrease of 5-HT levels in DD can be affected by two scenarios that usually bring about a reduction in neurogenesis. These two scenarios are as follows:

\section{Inhibition of serotonin synthesis}

When hypercortisolemia is sustained, the serotonin synthesis is inhibited through the stimulation of tryptophan 2,3-dioxygenase (TDO) enzyme located in the brain macrophages and microglial cells. ${ }^{44}$ The activation of TDO results in the production of several neuroactive metabolites from the kynurenine pathway and from some neurotoxics such as 3-hydroxykynurenine, 3-hydroxyanthraic acid, and the quinolinic acid. ${ }^{45}$

Quinolinic acid is an agonist of the glutamatergic NMDA receptors and favors the glutamatergic stimulation observed in proinflammation. ${ }^{46}$ It is believed that the activation of the inflammatory pathways in the brain contributes to the neurotrophic process through excitotoxicity and OS. ${ }^{38}$ The presence of free radicals (FR) generated by the excitotoxicity and OS interferes with the signal transduction systems, because the membrane receptors are highly sensitive to lipid peroxidation. This causes a reduction in the density of the receptors, thus affecting the coupling mechanisms between the binding of the ligands $\alpha$ and $\beta$ adrenergic, cholinergic, and serotoninergic (5-HT1A, 5-HT1B, and 5-HT2) ${ }^{47}$ through lipoperoxidation and apoptotic mechanism leading to the loss of glial elements. ${ }^{48}$ The excitatory action exerted by the quinolinic acid within the microglial triggers the participation of substances with immune-mediating activity and of the neurotransmitters such as prostaglandins, excitatory aminoacids, and nitric oxide.

\section{Participation of proinflammatory cytokines}

The participation of proinflammatory cytokines in DD was proposed by Smith ${ }^{63}$ in his "macrophage theory of depression" and later studied by Maes ${ }^{64}$ in the beginning of the 1990s. According to the theory, patients with severe clinical depression have an acute inflammatory phase response that explains the increase in blood concentration of proinflammatory biomarkers that are responsible for the different clinical aspects of depression such as hyperactivity of the HHS axis and altered metabolism of the serotonin and NA. ${ }^{49}$

The proinflammatory cytokines, mainly ILs, alpha and beta IFNs, and tumor necrosis factor (TNF), are capable of modulating the functioning of macrophages, glial and 
endothelial cells, and even neurons, because these cells possess specific receptors for these signaling molecules. ${ }^{50}$

It has been described that IL- $1 \beta$ and TNF- $\alpha$ are involved in behavioral manifestation of depressed patients. ${ }^{51}$ These molecules trigger a cascade of reactions that re-enforce the glutamatergic actions by inducing the activity of extrahepatic 2,3-dioxigenase enzyme present in the macrophages, dendrites, and in all the brain tissues. This induction favors the degradation of tryptophan toward the production of kynurenines, thus reducing serotonin levels. ${ }^{52}$

While IFN- $\gamma$ abates the expression of serotonin 5-HTA1 receptor and participates in the regulation of DA synthesis, INF decreases the concentrations of tetrahydrobiopterin (BH4), a co-factor necessary for the synthesis of dihydroxyphenylalanine - an immediate precursor of DA.

The reduction of DA has an impact on the increase of nitric oxide (NO) by activating BH4-dependent nitric oxide synthase enzyme in the microglial. NO is a gaseous neurotransmitter that stimulates the glutamatergic system that at low concentrations acts as second messenger in the release of DA and NA, but causes nitration and hypernitrosilation $(\mathrm{R}-\mathrm{N}=\mathrm{O})$ of amino acid and proteins when it exceeds the physiologic limit and this favors an excessive formation of other extremely reactive substances such as NO-tyrosine, NO-tryptophan-NO-arginine, and NO-serum albumin..$^{53}$ Frequently, DD is accompanied by digestive tract inflammation due to the increase of gram-negative enterobacteria such as Pseudomonas aeruginosa, Morganella morganii, Pseudomonas putida, and Citrobacter koseri. This intestinal microbiota forms part of a complex network called microbiota-gut-brain axis that influences the local immune response by stimulating the synthesis of $\operatorname{IgA}$ and IgM directed toward bacterial lipopolysacchrides and reactive aminoacids such as NO-tyrosine, NO-tryptophan, and NO-arginine. It also participates in the release of enteroendocrine neuropeptides and hormones, thereby favoring the synthesis and release of neurotransmitters and short-chain fatty acids. In addition, it contributes in the activation of HPA axis..$^{54}$ The activation of proinflammatory pathways in the brain contributes to neurotrophic dysfunction associated with anatomical brain modification through mechanisms of excitotoxicity and OS.

\section{Excitotoxicity and OS}

The excitotoxicity refers to overstimulation of inotropic receptors of glutamate and kainic acid both of which are capable of unbalancing the calcium ion entry into the neurons, thus activating the enzymatic degradation of membrane proteins, and favoring the synthesis of nitric oxide (NO) and the generation of FR. The presence of reactive molecules such as $\mathrm{O}^{-\mathrm{o}}, \mathrm{H}_{2} \mathrm{O}_{2}$, and $\mathrm{OH}^{-\mathrm{o}}$ enhances damage to proteins, lipids, sugar, and DNA and promotes the release of proapoptotic factors and energy failure. ${ }^{55,56}$

In normal conditions, the FR are the result of mitochondrial and peroxisomal metabolism. They also come as byproducts derived from the activation of MAO, an enzyme involved in the deactivation of the monoaminergic neurotransmitters (serotonin, DA, NA, and A) involved in the physiopathology of depression. ${ }^{36}$ They also play an important role in the regulation of several processes such as apoptosis and phagocytosis, the activation of some transcription factors and the signaling pathways in the organism, ${ }^{57}$ and, with the immune system, inactivation and elimination of pathogenic agents (virus and bacteria).

OS is closely related with mitochondrial dysfunction and electron $\left(e^{-}\right)$transport. An interruption in the transport of $e^{-}$ leads to a decrease in ATP production and oxidative damage in the membrane lipids, proteins, and nucleic acids, which brings about the activation of apoptosis. The damage exerted in the cell membranes alters the cytoskeleton and modifies the interactions between glial and neuronal cells. Moreover, it has an impact on proliferation and differentiation that are necessary for survival (neurogenesis) and neuroplasticity.

The oxidative damage affects the expression, folding, and secretion of the so-called brain-derived neurotrophic factor and type 1 insulin growth factor, the levels of which are reduced in the serum of patients with depression and bipolar disorder. Sustained increase of oxidative stress (OS) and excitotoxicity by glutamate stimulates the action of nuclear transcription factor $\mathrm{\kappa B}$ activating the production of IL- 6 and IL-8, thus establishing a circuit of inflammatory, excitotoxicity, and oxidative damage. ${ }^{57}$

Given the damage generated by OS, astrocytes try to attenuate the inflammatory and apoptotic response through various neuroprotection pathways. In the last decade, the protection and secretion of erythropoietin detected in the hippocampus, the internal capsule, the cortex, the mesencephalon, and the cerebral endothelium of patients with MDD have been proposed as a neuroprotective mechanism due to erythropoietin function as growth factor and promoter of neuroplasticity. Erythropoietin belongs to the family of the cytokines and in the nervous system exerts an autocrine, paracrine, and endocrine function. Its effectiveness is aimed at blocking apoptosis and at attenuating inflammatory response. ${ }^{58}$

The overproduction of cytokines impacts on the production and release of neurotransmitters. The consequence is 
an alteration in the density of packaging of neurotransmitters, decrease of neuronal size, and reduction of cortical glial cell number that coincides with the neuroanatomical findings characterizing DD. The imbalances generated by mitochondrial dysfunction cause a greater generation of RS, which stimulate the microglia to synthesize proinflammatory cytokines, establishing bidirectional communication that is exacerbated with each depressive episode. ${ }^{55}$

Currently, the chronic activation of microglia is an indicator of neuroprogression in patients with MDD associated with overexpression of the translocator protein located in the external mitochondrial membranes. This $18 \mathrm{kD}$ protein is associated with a longer duration of untreated diseases in patients with MDD. While the production of RS within the mitochondria stems from a decrease in the efficiency of antioxidant cellular defenses as well as from the alteration in calcium homeostasis in the organization of the membrane, the endoplasmic reticulum tries to offer an adaptive response or directed protection to restore the homeostasis within the cell through the mechanism described as "unfolded protein response (UPR)" the main objective of which is to prevent apoptosis. However, when the stress stimulus is prolonged, the UPR-related pathways can interact reciprocally with immunoinflammatory, neuro-oxidative, and neuro-nitrosative mechanisms, which are believed to play an important and shared pathophysiologic role that potentiates the neurodegenerative process. ${ }^{59}$

The different neuronal cells vary in their morphology and biochemical characteristics. Because of this diversity, each neuronal population has a unique molecular composition that determines its vulnerability to OS. Within these differences is the observation that different subpopulations of the hippocampus, substantia nigra, and neurons of the cerebral and cerebellar cortices are more susceptible to OS. ${ }^{60}$

The clinical reports of depressed patients show a high index in the systemic markers of OS and proinflammatory cytokines, which correlate with the severity of the crisis.

\section{Neuroprogression/neurodegeneration}

These two processes are accompanied by mechanisms of inflammation, OS (O and $\mathrm{N})$, and metabolic disorder.

Strictly speaking, neuroprogression is defined as the neuronal changes that include apoptosis, intracellular signaling dysfunction, and decrease in plasticity as well as in neurogenesis, which generate a pathologic reorganization. These processes have a mild onset in the diseases of behavior and are gradually exacerbated in each episode of crisis.

Neurodegeneration, on the other hand, is characterized by mild changes in the motor, sensory, or cognitive neuronal populations that, over time, become chronic, affecting the neuronal functions and advanced age-associated behavior in individuals. ${ }^{61}$ All neurodegenerative disorders involve abnormal processing of neuronal proteins. The protein particle that is incorrectly processed determines the malfunction of specific set of neurons and, therefore, the clinical manifestation of the disease. ${ }^{62}$

\section{Expectatives}

Currently, MDD is recognized as an accelerated and aggressive, neurotoxic, and neurodegenerative process that incapacitates the patient. This neuroprogressive mechanism involves multiple and complex interactions between the nervous, endocrine, and immune systems including genetic and environmental factors, inflammatory processes, presence of OS, neuroprotection deficit, and failed or incorrect reorganization in the neuroplasticity. The end results are poor response to treatment and increase in depressive episodes with the latter being the principal cause of the decline in cognitive and behavioral functions.

\section{Acknowledgments}

We thank Dr Cyril Ndidi Nwoye, a native English speaker and language professor, for the critical review and translation of this manuscript. This research received no specific grant from any funding agency in the public, commercial, private, or not-for-profit sectors.

\section{Author contributions}

All authors contributed toward data analysis, drafting and revising the paper, gave final approval of the version to be published, and agree to be accountable for all aspects of the work.

\section{Disclosure}

The authors report no conflicts of interest in this work.

\section{References}

1. American Psychiatric Association (APA). [DSM-5. Diagnostic and Statistical Manual of Mental Disorders] Manual Diagnóstico y Estadístico de los Trastornos Mentales. DSM- $5^{\circledR}$. American Psychiatric Association. EAN: 9788498358100. 5a Edition. 2014.

2. Zarragoitía AI. Depression. Generalities and particularities [Depresión. Generalidades y particularidades]. Vol. 6; 2011:978-1-138.

3. Carvajal C. Stress and depression: a look from the clinic to neurobiology [Estrés y depresión: Una mirada desde la clínica a la neurobiología]. Rev Méd Clín Condes. 2005;1684:210-219.

4. Eguíluz UI. History of psychopharmacology [Historia de la Psicofarmacología] In: Treaty of Psychopharmacology [Tratado de Psicofarmacología] CEditorial Médica Panamericana. 2010;3-13.

5. Díaz-Villa BA, González-González C. News in neurobiology of depression [Actualidades en neurobiología de la depresión]. Rev Latinoam Psiquiatr. 2012;11:106-115. 
6. Sequeira CA, Fornaguera TJ. Neurobiology of depression [Neurobiología de la depresión]. Rev Mex Neurociencias. 2009;10:462-478.

7. Heerlein A. Pharmacological antidepressants treatments [Tratamientos farmacológicos antidepresivos]. Rev Chil Neuropsiquiatr. 2002; 40(1s):21-45.

8. Sánchez AJ. Psychopharmacology of depression [Psicofarmacología de la depresión]. CM Psicobioquímica. 2013;2:37-51.

9. Fuchs E, Czéh B, Kole MH, Michaelis T, Lucassen PJ. Alterations of neuroplasticity in depression: the hippocampus and beyond. Eur Neuropsychopharmacol. 2004;14(Suppl 5):s481-s490.

10. Zandio M, Ferrín MJ, Cuesta MJ. Neurobiology of depression. Anales del Sistema Sanitario de Navarra. 2002;25(suppl 3):43-62.

11. Drevets WC, Price JL, Furey ML. Brain structural and functional abnormalities in mood disorders: implications for neurocircuitry models of depression. Brain Struct Funct. 2008;213(1-2):93-118.

12. Rajmohan V, Mohandas E. The limbic system. Indian J Psychiatry. 2007; 49(2):132-139.

13. Wainwright SR, Galea LA, Steven R, Wainn W, Liisa AMG. The neural plasticity theory of depression: assessing the roles of adult neurogenesis and PSA-NCAM within the hippocampus. Neural Plast. 2013; 2013:14pp.

14. Miguel Hidalgo JJ, Rajkowska G. Brain morphological changes during depression. Can they be reversed by antidepressants? [Cambios morfológicos cerebrales durante la depresión. ¿Pueden ser revertidos por los antidepresivos?] CS Drugs. 2002;16(6):361-372.

15. Guadarrama L, Escobar A, Zhang L. Neurochemical and neuroanatomical bases of depression [Bases neuroquímicas y neuroanatómicas de la depresión]. Rev Fac Med Univ Nac Auton Mex. 2006;49(2):66-72.

16. von Gunten A, Fox NC, Cipolotti L, Ron MA. A volumetric study of hippocampus and amygdala in depressed patients with subjective memory problems. J Neuropsychiatry Clin Neurosci. 2000;12(4): 493-498.

17. Nestler EJ. Antidepressant treatments in the 21st century. Biol Psychiatr. 2010;44(7):526-533.

18. Duval F, Gonzalez F, Rabia H. Neurobiology of stress [Neurobiologia del estrés]. Rev Chil Neuro-psiquiatr. 2010;48(4):307-318.

19. Tafet GE, Idoyaga-Vargas VP, Abulafia DP, et al. Correlation between cortisol level and serotonin uptake in patients with chronic stress and depression. Cogn Affect Behav Neurosci. 2001;1(4):388-393.

20. Tafet GE, Toister-Achituv M, Shinitzky M. Enhancement of serotonin uptake by cortisol: a possible link between stress and depression. Cogn Affect Behav Neurosci. 2001;1(1):96-104.

21. Goodale EP. The role of norepinephrine and dopamine in depression [El papel de la norepinefrina y de la dopamina en la depresión]. Rev Toxicomania Salud Mental. 2007;50:19-22.

22. Bahena-Trujillo R, Flores G, Arias Montaño JA. Dopamine: synthesis, release and receptors in the central nervous system [Dopamina: Síntesis, liberación y receptores en el sistema nervioso central]. Rev Biomed. 2000;11:39-60.

23. Duval F, Mokrani MC, Bailey P, et al. Serotonergic and noradrenergic function in depression: clinical correlates. Dialogues Clin Neurosci. 2000;2(3):299-308.

24. Heninger GR, Delgado PL, Charney DS. The revised monoamine theory of depression: a modulatory role for monoamines, based on new findings from monoamine depletion experiments in humans. Pharmacopsychiatry. 1996;29(1):2-11.

25. Morrett A, Gorini A, Villa RF. Affective disorders, antidepressant drugs and brain metabolism. Mol Psychiatr. 2003;8:773-785.

26. Jesberger JA, Richardson JS. Neurochemical aspects of depression: the past and the future? Int J Neurosci. 1985;27(1-2):19-47.

27. Lohoff FW, Falk WL. Overview of the genetics of major depressive disorder. Curr Psychiatry Rep. 2010;12(6):539-546.

28. Fañanás L. Genetic bases of vulnerability to depression [Bases genéticas de la vulnerabilidad a la depresión]. An Sist Sanit Navar. 2002; 25(3):21-42.

29. Cassano P, Argibay P. Depression and neuroplasticity. Interaction of nervous, endocrine and immune systems. Medicina. 2010;70(2):185-193.
30. Torrades Oliva S. Anxiety and depression. Genetic evidence [Ansiedad y depresión. Evidencias genéticas]. OFFARM. 2004;23(3):126-129.

31. Lolich M, Holtznan JN, Rago C, Vázquez GH. Neuroprogression and cognition in bipolar disorders [Neuroprogresion y cognición en los trastornos bipolares]. Rev Argent Psiquiatr. 2015;26:265-275.

32. Post RM, Fleming J, Kapczinski F. Neurobiological correlates of illness progression in the recurrent affective disorders. J Psychiatr Res. 2012;46(5):561-573.

33. Kapczinski F, Vieta E, Andreazza AC, et al. Allostatic load in bipolar disorder: implications for pathophysiology and treatment. Neurosci Biobehav Rev. 2008;32(4):675-692.

34. Duman RS, Monteggia LM. A neurotrophic modelfor stress-related mood disorders. Biol Psychiatr. 2006;59:1116-1127.

35. Berk M, Kapczinski F, Andreazza AC, et al. Pathways underlying neuroprogression in bipolar disorder: focus on inflammation, oxidative stress and neurotrophic factors. Neurosci Biobehav Rev. 2011;35(3):804-817.

36. Tapia-Saavedra A. Oxidative stress and depression. A possible etiological role? [Estrés oxidativo y depresión. ¿Un posible rol etiológico?]. Rev Chil Neuro-psiquiatr. 2005;43(4):329-336.

37. Bakunina N, Pariante CM, Zunszain PA. Immune mechanisms linked to depression via oxidative stress and neuroprogression. Immunology. 2015;144(3):365-373.

38. Moylan S, Maes M, Wray NR, Berk M. The neuroprogressive nature of major depressive disorder: pathways to disease evolution and resistance, and therapeutic implications. Mol Psychiatry. 2013;18(5):595-606.

39. Hurley LL, Tizabi Y. Neuroinflammation, neurodegeneration and depression. Neurotoxicol Res. 2013;23(2):131-144.

40. Setiawan E, Attwells S, Wilson AA, et al. Association of translocator protein total distribution volume with duration of untreated major depressive disorder: a cross-sectional study. Lancet Psychiat. 2018;5(4):339-347.

41. Meyer JH. Neuroprogression and immune activation in major depressive disorder. Mod Trends Pharmacopsychiatry. 2017;31:27-36.

42. Djavadian RL. Serotonin and neurogenesis in the hippocampal dentate gyrus of adult mammals. Acta Neurobiol Exp. 2004;64(2):189-200.

43. Mann JJ. Role of the serotonergic system in the pathogenesis of major depression and suicidal behavior. Neuropsychopharmacology. 1999; 21(2 Suppl):99S-105S.

44. Suzuki S, Toné S, Takikawa O, Kubo T, Kohno I, Minatogawa Y. Expression of indoleamine 2,3-dioxygenase and tryptophan 2,3dioxygenase in early concepti. Biochem J. 2001;355(Pt 2):425-429.

45. Oxenkrug G. Serotonin-kynurenine hypothesis of depression: historical overview and recent developments. Curr Drug Targets. 2013;14(5): 514-521.

46. Lamers F, Vogelzangs N, Merikangas KR, de Jonge P, Beekman AT, Penninx BW. Evidence for a differential role of HPA-axis function, inflammation and metabolic syndrome in melancholic versus atypical depression. Mol Psychiatry. 2013;18(6):692-699.

47. Gould E. Serotonin and hippocampal neurogenesis. Neuropsychopharmacology. 1999;21(2 Suppl):46S-51S.

48. Sadek N, Nemeroff C. Update in neurobiology of depression [Actualización en neurobiología de la depresión]. Rev Psiquiatr Urug. 2000;64(3):462-485.

49. Dantzer R, O'Connor JC, Freund GG, Johnson RW, Kelley KW. From inflammation to sickness and depression: when the immune system subjugates the brain. Nat Rev Neurosci. 2008;9(1):46-56.

50. Sirera R, Pedro T, Sánchez PT, Carlos Camps C. Immunology, stress, depression and cáncer [Inmunología, estrés, depresión y cáncer]. PsicoOncology. 2006;3(1):35-48.

51. Navas C, Zapata D. Immunological aspects in depression [Aspectos inmunológicos en la depresión]. Rev Venez Oncol. 2009;21(4):244-252.

52. Almond M. The relationship between depression and inflammation [La relación entre depresión e inflamación]. Curr Psychiatr. 2013;12: 25-32.

53. Maes M, Galecki P, Chang YS, Berk M. A review on the oxidative and nitrosative stress (O\&NS) pathways in major depression and their posible contribution to the (neuro) degenerative processes in that illness. Prog Neuro-Psycopharmacol Biol Psychiatr. 2011;35:676-692. 
54. Rea K, Dinan TG, Cryan JF. The brain-gut axis contributes to neuroprogression in stress-related disorders. Mod Trends Pharmacopsychiatry. 2017;31:152-161.

55. Dong XX, Wang Y, Qin ZH. Molecular mechanisms of excitotoxicity and their relevance to pathogenesis of neurodegenerative diseases. Acta Pharmacol Sin. 2009;30(4):379-387.

56. Leonard BE. The concept of depression as a dysfunction of the immune system. Curr Immunol Rev. 2010;6(3):205-212

57. Vavákova M, Durackova Z, Trebaticka J. Markers of oxidative stress and neuroprogression in depression disorder. Oxid Med Cel Longev. 2015;2015:898393.

58. Ma C, Cheng F, Wang X, et al. Erythropoietin pathway: a potential target for the treatment of depression. Int J Mol Sci. 2016;17(5):677.

59. Morris G, Puri BK, Walder K, et al. The endoplasmic reticulum stress response in neuroprogressive diseases: emerging pathophysiological role and translational implications. Mol Neurobiol. 2018;29:1-23.
60. Diaz-Hung ML, González-Fraguela ME. Oxidative stress in neurological diseases: cause or consequence? [El estrés oxidativo en las enfermedades neurológicas:¿Causa o consecuencia?]. Neurology. 2014;29(8):451-452.

61. Stanley B, Prusiner SB, Shattuck L. Neurodegenerative diseases and prions. New Engl J Med. 2001;344(20):1516-1526.

62. Ross CA, Poirier MA. Protein aggregation and neurodegenerative disease. Nat Med. 2004;10(Supp1 7):S10-S17.

63. Smith RS. The macrophage theory of depression. Med hypotheses. 1991;35(4):298-306.

64. Maes M, Maes L, Suy E. Symptom profiles of biological markers in depression: a multivariate study. Psychoneuroendocrinology. 1990; 15(1):29-37.
Neuropsychiatric Disease and Treatment

\section{Publish your work in this journal}

Neuropsychiatric Disease and Treatment is an international, peerreviewed journal of clinical therapeutics and pharmacology focusing on concise rapid reporting of clinical or pre-clinical studies on a range of neuropsychiatric and neurological disorders. This journa is indexed on PubMed Central, the 'PsycINFO' database and CAS,

\section{Dovepress}

and is the official journal of The International Neuropsychiatric Association (INA). The manuscript management system is completely online and includes a very quick and fair peer-review system, which is all easy to use. Visit http://www.dovepress.com/testimonials.php to read real quotes from published authors.

Submit your manuscript here: http://www.dovepress.com/neuropsychiatric-disease-and-treatment-journal 